\title{
ASPECTOS TRANSFORMADORES DE LA EXPERIENCIA HUMANA A LA LUZ DE LA PRÁCTICA DE LA MEDITACIÓN DE ATENCIÓN PLENA
}

\author{
TRANSFORMING ASPECTS OF HUMAN \\ EXPERIENCE IN THE LIGHT OF THE PRACTICE \\ OF MINDFULNESS MEDITATION
}

Miguel IBÁÑEZ RAmos*

Investigador independiente

\begin{abstract}
Resumen: La experiencia humana, es resultado de un proceso complejo en el que se dan cita dos polos intrínsecamente unidos: por un lado, existen cambios en la relación corporal con el medio registrados por nuestro sistema perceptivo, y por otro, valoraciones mentales relacionales, que condicionan, no sólo la percepción, sino también la respuesta ante ese entorno. Ambos aspectos son inseparables: percepción y sensación sentida de un lado, y hermenéutica y lenguaje de otro. Ambos constituyen nuestra experiencia. El presente artículo es una reflexión desde la fenomenología y la filosofía perenne sobre estos aspectos de la experiencia humana y su relación con la práctica de la atención plena (mindfulness) como proceso transformador de la misma. Nos preguntamos ${ }_{i}$ En qué medida puede la práctica de la atención plena modificar o influir en la consciencia y en qué sentido produce un cambio en la experiencia humana y en su interpretación?
\end{abstract}

Palabras clave: Conciencia; Meditación; Mindfulness; Fenomenología;Experiencia; Budismo.

\footnotetext{
* Doctor en religiones comparadas. Máster en hermenéutica bíblica. DEA en filosofía. Director de Mindfulness-Research. Email: miguelibez@gmail.com
} 
AвSTRACT: Human experience is the result of a complex process in which two poles are united intrinsically: on the one hand, there are bodily changes related to the environment in which our perceptive system is involved. On the other, a series of relational mental assessments which condition, not only perception itself, but also the response to the environment. Both aspects are inseparable: perception and "feeling felt" and hermeneutics and language. Both constitute our experience. This article is a reflection from phenomenology and perennial philosophy on the constitutive aspects of human experience and its relation to the practice of mindfulness meditation as a transforming process of experience. In this sense we wonder: Can the practice of mindfulness modify or influence consciousness and in what sense does it produce a change in human experience and its interpretation?

KeY words: Consciousness; Mindfulness meditation; Phenomenology; Buddhism; Experience.

\section{Introducción}

Cuando utilizamos la expresión "he tenido una experiencia», en general, estamos aludiendo a la vivencia subjetiva de la realidad fruto de un proceso cognitivo complejo. Es decir, nos referimos a una manera específica de relacionarnos con lo que nos rodea. La experiencia se fundamenta en la sensaciónpercepción subjetiva de que hay una realidad diferente de nosotros. Pero ¿La experiencia realmente surge como una relación entre un algo experimentado como distinto y nosotros como sujeto experimentador? ¿Acaso nosotros mismos no somos ya un algo experimentado al mismo tiempo en la mentecuerpo? ¿Cuál es la diferencia, pues, entre la experiencia en primera persona (la que yo experimento) y la experiencia en tercera persona, resultado de la observación realizada por otros sobre los datos observables y comparables de los procesos cognitivos que sustentan la experiencia subjetiva y que son más o menos predecibles? 
La práctica de la atención plena es una forma diferente de establecer una relación consciente con nuestro entorno, lo cual constituye nuestra experiencia y permite el surgimiento del momento cognitivo ${ }^{1 .}$

En la base de la tradición de la sabiduría perenne, tanto de Oriente como de Occidente, el discernimiento de la experiencia es esencial para determinar en qué medida se lleva a cabo el proceso de integración personal que culmina en lo que se denomina despertar, iluminación o liberación, objeto último de la práctica de atención plena. Esta experiencia tiene resonancias corporeizadas y es el resultado de un nuevo modo de relación cognitiva que se define como una experiencia de consciencia no-dual.

En este trabajo nos planteamos esta cuestión esencial: ¿qué caracteriza a la experiencia humana y a qué nos referimos cuando hablamos de experiencia de atención plena y consciencia no-dual resultante?

\section{2. ¿Qué entendemos por experiencia?}

Según el fenomenólogo A. Gurwitsch (1979): «la actividad de la mente confiere al caos primordial de la sensibilidad la diversidad de modos de organización que encontramos en la experiencia». Y parafraseando a W. James (A Pluralistic Universe), Gurwitsch continúa: «A cada momento, surge un segmento de entre

1 Hablamos de momento cognitivo en coherencia con la filosofía budista del conocimiento como un continuo de consciencia o de momentos de consciencia. En este sentido, en el momento cognitivo se crean a la vez el sujeto y el objeto (mundo) estando ambos ínterrelacionados. El fenomenólogo Merleau-Ponty dice: «La adquisición más importante de la fenomenología estriba sin duda en haber unido el subjetivismo y objetivismo extremos en su noción del mundo o de la racionalidad. El filósofo trata de pensar al mundo, al otro y a sí mismo y concebir sus relaciones. Pero el Ego meditante, el "espectador imparcial" [...] no llegan hasta una racionalidad ya dada, "se establecen" y la establecen con una iniciativa que no tiene ninguna garantía en el ser y cuyo derecho se apoya por entero en el poder efectivo que ésta nos da de asumir nuestra historia. El mundo fenomenológico no es la explicitación de un ser previo, sino la fundación, los cimientos, del ser». Merleau-Ponty, M. (1994). Fenomenología de la percepción, Planeta Agostini: Barcelona. pp. 19-20. 
la masa caótica e inarticulada, el cual se pone de relieve y a punto para ser nombrado e identificado por la facultad conceptiva»².

Este acontecer tiene dos elementos. Por un lado, se explica por el hecho de que la parte misma resalta y «sobresale» ante nuestro sistema perceptivo y la atención selectiva lo fija en la conciencia, y por otro, porque puede ser nombrado e identificado y comunicado. Poseemos una facultad que es capaz de separar, delimitar y extraer partes de entre la corriente concreta y continua de interacción ${ }^{3}$.

Así pues, la experiencia es el procesamiento consciente del resultado de la atención selectiva sobre el conjunto de interacciones que se producen con nuestro medio de forma consciente. La importancia que tiene la experiencia como forma de relacionarnos con nuestro medio ambiente es tal, que precisamente según se va desarrollando la experiencia, así también nosotros mismos nos vamos configurando. La experiencia no sólo se reduce al resultado de la interacción inmediata con lo que nos rodea, sino que modula el proceso de interacción biofísica (corporeizada) con el entorno y su comprensión (consciente) bajo la acción selectiva de la atención. Nosotros nos construimos en el acto mismo de comprensión como sujetos y así nos mostramos a nuestra consciencia. La propia experiencia nos cambia haciendo que ese cambio influya en la siguiente experiencia, y en último término, también en nuestra especie.

Este dato lo ha puesto de relieve especialmente el estudio de la neuroplasticidad $^{4}$ que muestra la capacidad cambiante de las sinapsis para crear mapas cerebrales de modo sucesivo. Así pues, la experiencia no es algo fijo y preestablecido

2 Gurwitsch, A. (1979), p. 41.

3 Este término genérico de interacción denota por un lado el trasfondo inconsciente en el que nuestro sistema está codificando cantidades ingentes de información y respuestas inmediatas inconscientes (control de temperatura, presión arterial, movimientos inconscientes, etc.), como un flujo del que luego, y casi al mismo tiempo, una parte reducida de información aflorará a la conciencia adoptando la forma de percepciones y pensamientos-emociones que provocarán acciones concretas y conductas resultantes.

4 Este cambio constante es debido a la neuroplasticidad adaptativa: Se refiere a las remodelaciones sinápticas que ocurren durante la edad adulta. Como consecuencia de la estimulación, se forman nuevas sinapsis, se remueven aquellas menos útiles y se transforman o refuerzan las existentes. Dependen de la experiencia por lo cual son numerosas durante los periodos de nuevos e intensos aprendizajes, o escasas si la actividad intelectual, motora o la estimulación sensorial son limitadas (Valadez 2007). Los cambios ligados a la experiencia también están ligados a la repetición. Las modificaciones sinápticas evolucionan y se consolidan con el tiempo (Karni 1997): http://www.neuromexico.org/2015/02/28/como-se-recupera-elcerebro-despues-de-una-lesion/ 
meramente como consecuencia al proceso cognitivo, sino que forma parte íntima del mismo y se construye momento a momento.

B. Lipton (2008) dice que nuestra experiencia se sustenta en la epigenética de nuestras células que van incrementando procesos especializados hasta crear programas conductuales de respuesta a patrones de valoración previos de la relación con el medio, incluyendo el propio proceso cognitivo consciente (pensamientosemociones). En algunos casos la consciencia enfocada por la atención se orienta a justificar la conducta predeterminada de forma inconsciente 5 .

Nuestro sistema cognitivo no sólo identifica parcelas del flujo de energía con el que nos relacionamos ${ }^{6}$, sino que además valora y jerarquiza esas relaciones y las enmarca dentro de un contexto cultural, añadiendo al valor emocional individual un nivel social o comunitario que trasciende al individuo. Este es el plano hermenéutico de la experiencia que tiene un carácter transpersonal y cultural a la vez.

Dicho esto, analicemos ahora cuál es el proceso constructivo y los distintos niveles por los que la relación con la realidad se convierte en experiencia, es decir, en proceso cognitivo consciente, modulador de nuestra conducta. El primer nivel de la experiencia lo vamos a denominar sensación sentida para después pasar al plano de la hermenéutica valorativa y de la experiencia comunicada.

\footnotetext{
5 En este sentido, el propio Lipton ha profundizado en las bases del medio en el que se desenvuelven nuestros aproximados 35 billones de células, para concluir que la genética no es determinante, sino que lo es más el medio (PH de la sangre, presión, hormonas, etc.) y éste está condicionado por los procesos cognitivos y eso influye, a su vez, en la expresión genética; en último término, nuestros procesos mentales, tanto conscientes como inconscientes, repercuten en nuestro cuerpo. Vid. Lipton, B. (2007) p. 165 ss. En el mismo sentido ver: Bargh, J.A.; Uleman, J.S.; Hassin, R.R. (2005), The New Unconscious, New York: Oxford University Press, p. 45.

6 Siegel (2011) define la experiencia como un intercambio de energía e información con el medio en que nos desenvolvemos.
} 


\section{De la sensación sentida ${ }^{7}$ a la mente auto-consciente}

Los fenomenólogos consideran la percepción como un proceso de unificación, auto-organización, o intercambio de energía e información en frase de D. Siegel (2011), que nos da la sensación de que nos relacionarnos con el mundo representado en la mente. Entendemos aquí la mente, como el conjunto sucesivo de estados mentales fruto de la elaboración de mapas neurales que resultan de la interactuación permanente con el flujo de energía de nuestro medio ambiente y que pueden ser más o menos equivalentes en los miembros de una misma especie, gracias a los cuales tenemos una referencia común y compartida de lo que llamamos la realidad física en la que se desenvuelve nuestra vida.

Evidentemente, la mente es inaccesible desde el punto de vista de la observación objetiva y, por ello mismo, también la experiencia como resultado de los procesos mentales de los que deriva.

Nadie reproduce el contenido de una experiencia, incluso propia y para sí mismo, si no es elaborada y comunicada con un lenguaje dentro de un marco hermenéutico. Sin embargo, podemos acceder (como observadores) a sus manifestaciones físicas en el cuerpo (experiencia en tercera persona). Por esta razón la ciencia con su método experimental puede objetivar las relaciones entre nuestro cuerpo con su funcionamiento cognitivo observable y las conductas derivadas, incluido el lenguaje, que hacen referencia a una determinada experiencia subjetiva siempre íntima.

Este enfoque según Rosenweig y col. (2005) se puede resumir en tres tipos de intervención: la somática, la conductual y la de correlación. Los tres enfoques corresponden al mismo principio y es que la conducta influye en el cerebro y el cerebro en la conducta ${ }^{8}$. Sin embargo, queda fuera de la posibilidad de estudio

\footnotetext{
7 Este proceso ha sido el hilo conductor del sistema filosófico y psicoterapéutico denominado "focusing" de E. Gendlin, que según Barceló (2008) se basa en cuatro principios: 1. Experiencing: sensación sentida interiormente y corporeizada. 2. Interacción: estar presente como ser vivo ante otro. 3. Autenticidad: Vivir el presente junto con el pasado y futuro de forma integrada. 4. Orientación: Experiencia valorativa y orientada a un fin. Según nuestro punto de vista los puntos uno y dos son concomitantes. El impacto estimular hace surgir en el mundo mental la relación sujeto-objeto.

8 Vid. Damasio, A. (2010), pp. 151 ss.
} 
experimental el contenido de la experiencia misma como construcción mental de la realidad que permite que existan esas correlaciones de interactuación. Todos estamos familiarizados con la experiencia de nuestra mente que elabora imágenes que representan la realidad con las que nos relacionamos emocionalmente. En este segundo nivel, ya no se trata de meras sensaciones ante las que reaccionar, sino de conjuntos de impulsos integrados e interpretados por la mente y fijados en la memoria. Es decir, es la sensación fugaz y efímera, pero recordada «con sentido» la que constituye la experiencia interpretada, que es la única a la que tenemos acceso a nivel intersubjetivo cuando comunico mi experiencia.

El acceso a ese nivel de contenido de la experiencia sólo es posible gracias al lenguaje, a la comunicación simbólica y al relato de la experiencia, pero esto hace que la experiencia sea ya mediatizada por los procesos hermenéuticos y valorativos. En este sentido compartimos la reflexión de M.T. Román cuando dice: «¿Cuál es el papel que representa el "Club de las palabras" o la "Comunidad del lenguaje” en la vida del ser humano? Para algunos es el responsable del mundo de la dualidad en el que estamos inmersos»"

Este relato de la experiencia no es posible sin un proceso de comprensión previa. Ahora bien, de la vivencia a la comprensión hay un elemento esencial que determina tanto la comprensión misma a nivel personal, como la posible comunicación en el plano interpersonal. Este elemento es precisamente el marco hermenéutico.

En efecto, la característica de la experiencia humana es que funciona como un proceso que va de la sensación sentida y creación de mapas neurales correlativos, a la experiencia interpretada fruto de la comprensión y del lenguaje. Este proceso además se produce en el ámbito de la consciencia porque cuando hablamos de experiencia, hablamos de experiencia en la consciencia de vigilia, ya que a eso es a lo que denominamos experiencia real a diferencia del sueño, la ensońación, la imaginación y otras formas de contenido mental en la consciencia (sin incluir formas alternativas de conciencia como la alucinación o las experiencias derivadas del uso de enteógenos u otros métodos). Por último, este proceso se manifiesta en la consciencia en forma de un sujeto conocedor que percibe un objeto conocido, por eso lo llamamos consciencia dual.

9 Román López, M. T. (2017), p. 38. 
Si queremos entender en qué se basa la práctica milenaria de la atención plena y cuál es su efecto transformador en nuestra experiencia personal, debemos comprender qué elementos y características configuran el tipo de experiencia que tenemos espontáneamente y cuál es la naturaleza de la percepción fruto de la práctica intencional que llamamos meditación de atención plena.

Una característica esencial de la experiencia humana según A. Damasio (2010) es que «la formación de mapas neuronales a partir de los distintos estímulos procedentes de los sentidos se realiza por capas cada vez más complejas e integradas ${ }^{10 .}$ La complejidad de estas capas se relaciona con la especificidad de la consciencia humana y su impacto en nuestra supervivencia. Estas capas siguen un patrón de integración vertical que se va elaborando a nivel cerebral desde el tronco encefálico hasta el neocórtex concretando y modulando a lo largo del proceso la información que más nos favorece para responder al momento cognitivo según las necesidades. Es decir, la cognición es un sistema adaptativo orientado a la supervivencia.

Podemos resumir las características del proceso de génesis de la experiencia humana de la siguiente manera:

1. Sucesión-continuidad. Ya hemos dicho que la experiencia surge de la interactuación con la realidad cambiante momento a momento. La percepción es instantánea, sucesiva y constante (normalmente no hay vacíos de percepción, sino cambios de enfoque y objeto durante la vigilia), la percepción fluye sin detenerse.

Ahora no estamos hablando de los contenidos de las sensaciones ya elaboradas en el momento cognitivo, sino del mero sentir: del estímulo traducido a lenguaje neuronal como inicio de la percepción. En este punto vemos una primera ilusión: en nuestra experiencia se ve la realidad fija y estable. A la sucesión de momentos cognitivos cambiantes, nuestra mente le asigna una correlación neuronal también cambiante, instante a instante, lo que genera una sensación de continuidad, de presencia fija y estable, que luego será recordada por la memoria. La realidad como tal es inasible, cambia constantemente y no es tal y como nos aparece: estable y permanente.

10 Vid. Damasio, A. (2010). "Y el cerebro creó al hombre. ¿Cómo pudo el cerebro generar emociones, sentimientos, ideas y el yo? Editorial Destino: Barcelona, pp. 110-112. 
Según A. Damasio (2010), los mapas cerebrales son volubles, cambian de un momento a otro para reflejar los cambios que ocurren en las neuronas que los alimentan y que, a su vez, reflejan los cambios en el interior del cuerpo y en el mundo a nuestro alrededor. Nosotros percibimos los cambios en las cosas, el deterioro, y la transformación, pero como a saltos y lo asociamos a un patrón de tiempo más o menos largo y no al cambio incesante, momento a momento que es en general imperceptible.

No percibimos la realidad como cosas, sino como «fenómenos». Este concepto elaborado por E. Husserl, y desarrollado posteriormente por la escuela fenomenológica representada por Merleau-Ponty, A. Gurwitsch o F. Varela (neurofenomenología) nos acerca más a la visión de la atención plena. Este enfoque filosófico es en frase de Merleau-Ponty:

Una filosofía trascendental que deja en suspenso, para comprenderlas, las afirmaciones de la actitud natural, siendo además una filosofía para la cual el mundo siempre «está ahí», ya antes de la reflexión, como una presencia inajenable ${ }^{11}$.

Desde el punto de vista filosófico esta descripción de la experiencia nos sitúa ante un problema epistemológico esencial. Si sólo los fenómenos son los que emergen en el campo de mi consciencia, ya existe una elaboración cognitiva de base a mi experiencia. Así pues, ¿Puede la consciencia captar o abrirse a una experiencia con un marco de elaboración cognitivo diferente, o incluso sin marco de elaboración? ${ }^{212} Y$ si así fuera, ¿cuáles serían las consecuencias en nuestra experiencia? Esta pregunta nos sitúa una vez más en el proceso de integración de la hermenéutica de la experiencia defendido por algunos neurólogos y acorde con la filosofía de H.-G. Gadamer ${ }^{13}$. La experiencia es flexible y moldeable porque

11 Merleau-Ponty, M. (1994), p. 7.

12 Aquí surge un problema filosófico que no vamos a tratar, pero conviene apuntarlo: Lo que sentimos es real, pero lo que nosotros experimentamos y con quien nos relacionamos es con la correlación mental de algo que no sabemos lo que es en verdad. A este flujo de energía en el que nos desenvolvemos lo llamamos protofenómeno que no es otra cosa que lo anterior a la percepción.

13 En su obra principal, Wahrheit und Methode, Gadamer se plantea la verdad como un acontecer de sentido que sólo se puede dar dentro de un marco de interpretación, el cual 
es una interacción y un proceso de integración. El fenómeno, lo es precisamente por ser «cognitivo» y el hecho de ser cognitivo lo sitúa en el desencadenante de un proceso subjetivo que abre diversos espacios íntimos e irrepetibles y modifica la relación de un individuo concreto consigo mismo y con su entorno.

La experiencia denominada presencia plena (fruto del ejercicio de la atención plena) resulta de una forma especial de relacionarnos con la realidad ${ }^{14}$, en la que entran en juego diversas conductas intencionalmente dirigidas a enfocar la atención de una manera diferente (meditación, conciencia dinámica corporal, exploración corporal, etc.) y una de sus características es enfocarse en los procesos psico-corporales momento a momento. Este tema ha sido también objeto del estudio fenomenológico como demuestra el siguiente texto de Ravagnan, (1965):

Esta noción de contemporaneidad y actualidad nos conduce, con Henri Ey, al examen de su estructura misma con el fin de lograr la aprehensión de uno de sus momentos fundamentales, particularmente en la circunstancia en que emerge en la fugacidad del presente como una experiencia vivida. Tal actitud fenomenológica tendría que cumplir su cometido examinando la toma de conciencia como configuradora de un campo, tratando de advertir sus relaciones operacionales con la realidad, y si accedemos a -la sistematización de Ey, a la penetración en el ser consciente precisamente allí donde él se constituye en presencia y sujeto de sus propias experiencias ${ }^{15}$.

Para comprender más profundamente cómo influye la mente en este proceso y los mecanismos que implica, nos resulta muy esclarecedora la aportación del pensamiento oriental, en especial el pensamiento vedanta advaita y budista, pues durante siglos se han dedicado a analizar y desarrollar esta práctica. Dice Varela (1997) al respecto:

equivale a un tipo de mirada durante el proceso cognitivo.

14 Así lo define R. Siegel (2011), pp. 24 ss.

15 Ravagnan, L.M. (1965) "Concepción fenomenológica del campo de la consciencia" en, Revista de Psicología vol 2. p. 2 de la edición (on line) http://www.memoria.fahce.unlp.edu.ar/art_revistas/pr.861/pr.861.pdf 
Presencia plena significa que la mente, en efecto, está presente en la experiencia corpórea cotidiana tal y como sucede, en el momento que sucede. Se trata, no de observar el resultado de la experiencia en el recuerdo (pensamiento de la experiencia) sino de integrar la consciencia en el proceso mismo en su cualidad impermanente. De ahí nacen los conceptos de anicca y anatta (impermanencia de los fenómenos y ausencia de yo).

Ahora bien, ¿Cómo es una experiencia pre-conceptual, o siguiendo la línea trazada en este trabajo, una experiencia consciente pero no interpretada, carente de filtro hermenéutico?

Para responder a esta pregunta es necesario reflexionar sobre los niveles de integración que forman el proceso cognitivo que da lugar a la experiencia misma. Hay un nivel de cognición subconsciente (mente computacional según Jackendoff ${ }^{16}$ ) al que normalmente no tenemos acceso y que sigue sus patrones automatizados, que en parte son resultado de las experiencias anteriores.

Luego está la mente fenomenológica consciente, modulada por la atención. En esta modulación espontánea influye el nivel anterior inconsciente, por eso, el resultado de lo vivido conscientemente está muy condicionado ya que la atención limita el campo y lo hace muchas veces desde patrones inconscientes. Por último, surge el componente hermenéutico modulado por todo nuestro aprendizaje, lenguaje, cultura, creencias etc. y la dimensión relacional sobre la que construimos nuestro mundo de experiencia comunicada, como resultado de la comprensión. El tema es que no están separadas, ni mucho menos aisladas, sino que la una se construye sobre los cimientos de la otra siguiendo los patrones de integración de las capas, tal y como ya señalamos. Cuanto mayor presencia hay de la atención plena en el proceso en el que surge la experiencia, menor es la automatización de respuestas originadas en cada capa y mayor el número de elementos de la mente inconsciente que son integrados en la experiencia consciente, disolviendo los patrones condicionantes de reacciones automáticas establecidas y equilibrando la respuesta emocional. Por eso la experiencia se vive cada vez de forma menos fragmentada y con mayor perspectiva y contexto ${ }^{17}$.

16 Jackendoff, R. (1998), pp.40 y ss.

17 Este término, desautomatización es el usado por A.J. Deikman (2012) en relación con la práctica de la meditación.

ÉNDOXA: Series Filosóficas, n. ${ }^{\circ}$ 42, 2018, pp. 285 -308. UNED, Madrid 
La sensación sentida es evanescente, fluye de un momento a otro y en el fluir genera el fenómeno como momento cognitivo en la consciencia. Al vivir esta experiencia libre de la ilusión de continuidad y permanencia, la consciencia surgida de la atención plena se ve liberada del flujo (ilusorio) de los acontecimientos enlazados causalmente, por eso el budismo hablará del surgimiento condicionado de los fenómenos o dicho de otro modo la interdependencia de todos los fenómenos y su cualidad última de vacío de existencia inherente, lo que trae como consecuencia la ausencia de apego en el plano relacional (Pratîtyasamutpâda, es la denominación sánscrita de esta interpretación desarrollada principalmente en el texto clásico: Shâlistamba Sutra ${ }^{18}$ ).

2. Integración. La experiencia no es la suma de sensaciones, sino, como ya hemos dicho, es un proceso integrador constante y consciente. A este respecto el filósofo X. Zubiri (2004) dice: "Este proceso sentiente es estrictamente unitario: consiste en la unidad intrínseca y radical, en la unidad indisoluble de sus tres momentos, de suscitación, modificación tónica y respuesta». Según Zubiri, aunque distinguimos tres momentos en lo que él denomina "proceso sentiente», en realidad, la sensación sentida es un proceso que integra los tres: un «algo que sobresale en el flujo de experiencia», que a su vez modifica el tono vital, en un sentido o en otro, y que suscita una respuesta. Todo ello de forma continua e integrada.

A medida que la evolución nos ha dotado de mente cada vez más compleja, el proceso integrador también es más complejo. El neurocientífico y director del Mindsight Institute en la Universidad de California (UCLA) Daniel Siegel $(2011)^{19}$ observó que los sistemas más complejos son también los más adaptables, por lo que calificó al proceso de integración de la experiencia como flexible, adaptativo, coherente, energético y estable (FACES de las siglas en inglés). Según este autor, el proceso de integración se realiza en ocho ámbitos diferentes, y de este proceso depende el bienestar y la felicidad del individuo. Según dice: «el modo de centrar la atención es la clave para fomentar cambios integradores en el cerebro». Así pues, el proceso cognitivo-emocional consciente que llamamos experiencia tiende a integrar la información para aumentar la capacidad de adaptación entre el caos y la rigidez, que serían los polos de inadaptación. Esta integración de información es el paso previo e íntimamente relacionado con la identificación-comprensión de la que hemos hablado.

18 Tola, F; Dragonetti, C. (1980). El budismo Mahayana. Buenos Aires: Kier, p. 43.

19 D. Siegel (2011), pp.110-111. 
Precisamente aquí nace la segunda ilusión: El momento cognitivo es la identificación con la forma como estructura cognitiva emergente y la relación que se establece con ella, la cual según la filosofía budista puede ser de atracción, de rechazo o de indiferencia por lo que se insiste en el cultivo de la ecuanimidad para crear las condiciones favorables para la experiencia de la no forma. La forma surge en mi mente y atrae la atención / consciencia que se fija a ella en el momento cognitivo, pero la realidad es un "continuum» de posibilidades de ser fenómeno y éstas se «reducen $»^{20}$ en el momento en que surge la forma y me relaciono con ella. Por eso inquieta la pregunta ¿Es posible una consciencia de la no-forma, tal y como expresa la tradición de la atención plena?

La forma es el comienzo de la elaboración cognitiva de la experiencia y a medida que la mente condensa los estímulos y emerge la forma surge la identificación consciente con ella, y posteriormente, el nombre. Gracias al lenguaje lo cognitivo deviene un proceso narrativo coherente que marca la relación de un self con la forma ${ }^{21}$. Esto es denominado proceso de integración vertical (D. Siegel, 2011: p. 113) desde las estructuras más básicas del cerebro que procesan los estímulos-sensación (tronco encefálico-tálamo) pasando por el sistema límbico (procesamiento emocional-valorativo) hasta el neocórtex (pensamiento narrativoconceptual-analítico) haciendo que a esa identificación concreta le corresponda un «tono emocional» específico de atracción o rechazo.

La práctica de la atención plena prolongada, según los testimonios de los escritos de quienes practicaron este ejercicio, disminuye los vínculos de identificación con la forma, colocando la atención poco a poco en el espacio anterior al surgimiento de identificación con la misma. Los insight derivados de la práctica de la atención plena se interpretan como una liberación de la atadura o vínculo con la forma, a la vez que una comprensión de la verdadera naturaleza de la realidad fluyendo constantemente (tathagath ${ }^{22}$ ). Precisamente porque se trata de experiencias fuera de la identificación con la forma, el budismo māhāyana, en especial la escuela madhyamika de Nāgārjuna, profundizó en la denominada

20 Uso metafórico de la palabra reducción según la física cuántica.

21 Este tema fue desarrollado por la psicología Gestalt. En especial M. Wertheimer, W. Köhler y K. Koffka.

22 La corriente mahayana del budismo concibe la comprensión de la verdadera naturaleza de la realidad como no-conceptual o sabiduría no-discriminativa (nirvikalpajnana) Thich Nhat Hanh (1978), p. 55. 
experiencia del vacío (śünyata ${ }^{23}$ ) como respuesta a la pregunta de si es posible la consciencia de la no forma. La experiencia de comprensión del vacío en el que surgen los fenómenos abre la consciencia de manera ilimitada y no condicionada por forma alguna, aunque sea de manera fugaz, iniciando el camino de la experiencia a una comprensión de la realidad no condicionada, tal y como es en sí, sin principio ni fin.

Se podría argumentar ante lo dicho: ¿cómo puede haber comprensión o experiencia sin procesamiento hermenéutico? Sólo es posible si la experiencia carece de dualidad cognitiva (sujeto-objeto). En efecto, podríamos decir que se trata de una experiencia sin sujeto cognoscente ni objeto conocido. Como experiencia subjetiva lo vemos reflejado en el siguiente texto de la tradición Zen:

El camino perfecto carece de dificultad, sólo hay que evitar atrapar o rechazar. Cuando ambos, amor y aversión, están ausentes, todo se vuelve claro y diáfano, pero haz la más mínima distinción y el cielo y la tierra se distanciarán infinitamente ${ }^{24}$.

3. Comparación-Selección. A medida que la experiencia se va repitiendo, la memoria relaciona y compara los datos de la experiencia con otras experiencias similares. No nos referimos a la rememoración autoconsciente, sino también a la memoria inconsciente, sensitiva e incluso celular. En esta comparación también se produce una selección de estímulos en función de los principios de integración antes descritos.

Siguiendo a V. Simón (2006: p.11) podemos decir que en ese proceso de clasificación de la información que trata de hacer encajar todo lo nuevo en categorías y moldes viejos, es inevitable que se pierda una gran parte del material entrante, precisamente la más novedosa, la que no se deja asimilar fácilmente a las categorías previamente establecidas. El sistema actúa imponiendo una serie de filtros automáticos que resaltan los aspectos ya conocidos de la realidad y atenúan, o eliminan del todo, los aspectos novedosos de la misma.

\footnotetext{
23 Sobre la transformación de la visión del vacío de los Dharmas constitutivos de la realidad por parte de la filosofía mahayana ver: Harvey, P. (1998), pp. 124-125,

24 Sêng-ts'an, Hsin-hsin-ming (Inscripto en la mente creyente) Vid. Suzuki, D.T. (1981), Ensayos de budismo zen, Kier: Buenos Aires, pp. 214-219.
} 
Una de las funciones adaptativas de nuestro cerebro es generar una representación $^{25}$ de la realidad, coherente y con sentido completo, de forma que nuestros comportamientos sean adecuados.

Hans-Georg Gadamer, que recogió en su pensamiento, por un lado, la filosofía de la ciencia de la escuela neokantiana de Marburgo, y por otro la fenomenología de Husserl a través de Heidegger, puso de relieve el valor práctico de la verdad, entendida como un proceso de comprensión de carácter vital. Este proceso es la visión más profunda de la hermenéutica que elabora un constructo de sentido, resultado de una experiencia determinada. Según la visión fenomenológica (Gurwitsch 1979), la experiencia se mueve en el ámbito del fenómeno, fruto de la reducción eidética y es el único medio de acceso a lo que existe ${ }^{26}$. El paso del fenómeno a la comprensión subjetiva elaborada lo constituye el «proceso de sentido" cuyo objeto es modular la respuesta emocional y la conducta subsiguiente dentro de un contexto coherente de la vida.

De aquí surge la tercera ilusión: identificar la realidad con la experiencia creada por nuestro sistema cognitivo buscando dar sentido y coherencia a lo vivido. La consciencia está modulada por los procesos mentales y la mente crea la experiencia bajo el foco de la atención consciente generando expectativas que mantengan una cierta coherencia. Por eso la experiencia derivada de la atención plena se define como "despertar" o "liberarse" de los marcos mentales de interpretación y cuya respuesta es válida sólo ante el momento concreto y no como norma universal.

4. Experiencia autoconsciente. La experiencia humana se caracteriza por ser experimentada en un yo como proceso mental identitario que organiza la relación con la experiencia misma en una especie de «bucle» cognitivo. Este proceso además es compartido con otros seres humanos, creando la comunidad del lenguaje

25 El término «representación» no está usado en sentido de realismo ingenuo como si fuera una fotografía de la realidad que se corresponde tal cual y de forma especular. Tampoco estrictamente en el sentido usado por Schopenhauer cuando dice: «el mundo que le rodea no existe más que como representación, es decir, única y enteramente con relación a otro ser: el ser que percibe, que es él mismo». Schopenhauer, A. (2004) El mundo como voluntad y representación. Barcelona: RBA editores, p.41. Sino que la referencia que tenemos a lo real o al mundo es una creación representada mentalmente momento a momento en pleno cambio (en gran medida imperceptible) y sigue las reglas (coherencia) de dicha representación en la línea desarrollada por la fenomenología de Husserl.

26 No podemos detenernos ahora en explicar todo el proceso, vid: D. Siegel (2011), pp. 110-117. 
que permite desenvolverse en el «mundo humano». El paso previo (aunque no desde el punto de vista temporal ya que se produce a la vez) a compartir la experiencia es interpretarla. La interpretación es un estadio concomitante a la interactuación, a la reacción estimular con el flujo de experiencia momento a momento. Interpretar significa tres cosas: una, identificar parcelas de experiencia sentida (mapas); dos, investir de sentido (valoración) a esa experiencia, relacionándola con otras experiencias vividas bajo marcos de interpretación estructurales y culturales; y tres, crear una narración (causas y efectos) que exprese coherencia y que se relaciona con un sujeto (self-autobiográfico ${ }^{27}$ ).

Crear sentido no es sólo darse cuenta de algo (por eso distinguimos consciencia de autoconsciencia), ya que todo ser vivo se da cuenta de las alteraciones de su entorno y reacciona movido por la supervivencia o el bienestar; sino ir un paso más allá, se trata de expresar la relación y el vínculo que esa experiencia tiene con un "yo» como sujeto que percibe. La autoconsciencia es una consciencia reflexiva, es decir, que se vuelve sobre sí misma como una metaconsciencia (consciencia de los propios procesos cognitivos).

«El sistema» se hace conocedor, y a la vez, objeto de conocimiento. Para ello, nosotros nos representamos ante nuestra consciencia como una parcela de realidad sentida de una manera determinada. Este es un proceso muy complejo que ya Varela (1999) explicaba desde el concepto científico de emergencia:

A partir de este elemento local surge un proceso global, un estado global o nivel global, que ni es independiente de estas interacciones locales ni reducible a ellas. Se trata de la emergencia de un nivel global que surge a partir de las reglas locales; y que tiene un estatus ontológico diferente, porque trae consigo la creación de un individuo, o de una unidad cognitiva ${ }^{28}$.

Hoy día, se concibe el yo como propiedad emergente de la actividad neuronal y siguiendo a Varela (1999) diremos que, sin embargo, la afirmación inversa generalmente se pasa por alto. Esto es importante ya que, si los componentes $\mathrm{y}$ circuitos neurales funcionan como agentes locales, capaces de dar origen a un yo en forma emergente, de ello se deriva que este nivel global, el yo, tiene acciones eficaces directas sobre los componentes locales, y es precisamente en

27 Vid. Damasio, A. (2010), p. 48.

28 Varela, F. (1999). Four batons for the future of cognitive science, en Envissioning Knowledge, B. Wiens (ed.), Dumont Cologne, p. 4. 
esto en lo que se basa el principio de la práctica de la meditación. Es una calle de dos direcciones: los componentes locales dan origen a esta mente emergente, pero al mismo tiempo la mente emergente constriñe y afecta directamente a los componentes locales. Esta afirmación es fundamental para entender el proceso vinculado a la meditación mindfulness. En efecto, desde el yo-proceso mental $\mathrm{y}$ de forma intencional nosotros podemos influir en la experiencia ya que existe un vínculo de interacción.

5. Experiencia comunicada. Volviendo a Damasio (2010): La mente es la impresionante consecuencia de la incesante y dinámica elaboración de mapas en el cerebro. Cuando estos mapas crean patrones determinados nos formamos una idea de lo que nos rodea bajo esos patrones (sonidos, colores, formas, tacto, etc.) y a estos patrones es a los que A. Damasio denomina imágenes en un sentido amplio.

Las imágenes contienen todo contenido mental, desde pensamientos hasta emociones, y son imágenes creadas a partir de los mapas, momento a momento, y mezcladas con imágenes recordadas. En ese sentido las imágenes son los «ladrillos de lo que denominamos nuestra experiencia». La experiencia humana es pues un proceso que va de la sensación sentida a la experiencia interpretada; y de la experiencia interpretada a la experiencia comunicada.

Uno de los datos más importantes que nos han puesto de relieve los recientes estudios en neurociencia cognitiva es la importancia de la intersubjetividad y de la emoción en la construcción de la propia experiencia. Como ya indicaba Varela (1999: p. 8):

La mente no es la representación de un determinado estado de cosas; la mente es la producción constante de esta realidad coherente que constituye un mundo, un modo coherente de organizar las transiciones locales-globales [...] como consecuencia, uno de los descubrimientos más impactantes de los últimos años es que el afecto o la emoción está en el origen de lo que hacemos todos los días en nuestro manejo e interacción con el mundo. Las últimas investigaciones en ciencia cognitiva nos muestran claramente que la individualidad y la intersubjetividad no se oponen, sino que son necesariamente complementarias. 
La experiencia como resultado de un acto cognitivo es en sí misma «autorelatada" para ser comprendida y posteriormente comunicada. Pero la comunicación no es una acción superflua o añadida, sino que forma parte del mismo proceso experiencial. Cuando la experiencia es comunicada se asienta y se asume como experiencia social y verdaderamente humana. La comunicación tiene un componente inductivo que hace que esa experiencia en concreto pueda ser compartida. Es decir, en la construcción misma de la experiencia subjetiva usamos elementos comunicativos como el lenguaje para crear las relaciones contextuales de lo vivido y eso nos permite también compartirlo. De ahí nace en último término toda acción pedagógica como reconstrucción del proceso cognitivo en forma comunicativa; pero también el arte, la música, el teatro, la poesía y cualquier forma de expresión de la íntima experiencia.

Para comunicar una experiencia necesitamos sistemas de comunicación verbal y no verbal. Según Gadamer "cada individuo que asciende desde su ser natural hacia lo espiritual encuentra en el idioma, costumbres e instituciones de su pueblo una sustancia dada que debe hacer suya de un modo análogo a como adquiere el lenguaje» ${ }^{29}$. Este hacer suyo, es un proceso intencional. Exige necesariamente una focalización de la consciencia que hace que los contenidos adquieran significación. Así pues, según la modalidad de consciencia, la comunicación adopta una forma determinada. Como dice L.M. Ravagnan (1965: p. 3), «La intencionalidad se constituye, de tal modo, como el punto de partida que promueve la organización de un campo cuya raíz originaria es el sentido". Una vez más el sentido está más allá de la significación o denotación lingüística.

El lenguaje es una conducta humana que consiste en relacionar signos con percepciones sobre la base de un modo semejante de experimentar la realidad, no de una manera aleatoria sino preestablecida socialmente. Esta sería la base de la significación como consenso social. Ahora bien ¿Qué ocurre cuando se tiene que expresar una experiencia que está fuera del marco habitual de interpretación? En este caso vemos que el lenguaje adopta un carácter diferente. El lenguaje vinculado a la práctica de la meditación tiene más un carácter pragmático que semántico o significativo. Pasa a ser lo que en la tradición budista se denominan los «medios hábiles» $\left(\right.$ upaya $\left.{ }^{30}\right)$ de modo que más que comunicar la experiencia ayudan a vivirla.

29 Gadamer H.-G. (1993), p. 33.

30 Vid. Saddharma Pundarika (Sutra del Loto), cap.II. 
El sentido, tal y como nosotros lo entendemos, consiste en modular la relación cognitiva con la experiencia, construyendo una coherencia y equilibrio emocional subjetivo basado en los valores que otorgo a la experiencia. No hablamos del aspecto lingüístico del término, ni del debate filosófico entre denotación y connotación o sentido y significado ${ }^{31}$. El punto de vista que queremos resaltar es el psicológico, es decir, el conjunto de procesos mentales que hacen que establezcamos vínculos interpretativos a los acontecimientos según van sucediendo.

En el caso de la tradición de la atención plena se trasciende el sentido conceptual tal y como dice Thich Nhat Hanh (1978): «Por eso, hay que "matar" los conceptos de la realidad, para que la realidad pueda realizarse y revelarse. Matar al Buda es sin duda el único medio de ver a Buda» ${ }^{32}$.

Trascender el sentido es suprimir la elaboración mental proyectiva. El sentido es una derivada del sistema proyectivo de nuestro cerebro que crea vínculos en muchos casos supuestos entre los componentes de la experiencia. Como dice J. P. Changeux (1999): «nuestro cerebro atribuye significaciones permanentemente, veo que su mirada se dirige hacia la mía e intento anticipar su respuesta y lo que probablemente vaya a decirle en unos segundos ${ }^{33}$. El cúmulo de referencias proyectivas (significados) nos permite ir creando un universo de sentido a nivel subjetivo que muchas veces dista de la realidad. Trascender el sentido no es nihilismo ${ }^{34}$ sino suprimir cualquier forma de juicio mental sobre la experiencia.

Pero, la consciencia reflexiva o autoconsciencia se caracteriza por objetivar el hecho mismo de conocer para poderlo relacionar con el sujeto que conoce. De este modo, objeto conocido, sujeto que conoce y acto de conocer son como la descomposición de un rayo de luz en bandas de color diferentes en el instante de atravesar un prisma. Según Damasio (2010: p. 242), "la consciencia es un estado mental en el que se tiene conocimiento de la propia existencia y de la existencia del entorno».

31 Este debate filosófico ha sido tratado extensamente como refleja J. Lyons en su obra Semántica (1980) Barcelona: Teide, pp. 168-216.

32 Thich Nhat Hanh (1978). Claves del Zen. Sígueme: Salamanca, p. 34.

33 Ricoeur, P.; Changeux, J-P. (1999). Lo que nos hace pensar. La naturaleza y la regla. Barcelona: Península, p. 47.

34 Vid. V. Frankl (1987). El hombre doliente. Fundamentos antropológicos de la psicoterapia. Barcelona: Herder, pp. 200 ss. 
La característica de la experiencia interpretada o experiencia autoconsciente, tal y como ya dijimos anteriormente, es que es capaz de ser referida a un «ente virtual» emergente que llamamos self y que funciona como un proceso de identificaciones complejas que gestiona la experiencia y se sustenta en la representación del cuerpo en la mente a través del pensamiento, momento a momento.

Este proceso emergente identitario constituye el centro de nuestra existencia y es la respuesta evolutiva más importante para conseguir la supervivencia de nuestra especie (intencionalidad, planificación, aprendizaje etc. todo se sustenta en el ego), sin embargo, y esta es la cuarta ilusión, se trata de un proceso o un conjunto de procesos, no de una entidad o sujeto entitativo. El ego, nuestro yo identitario, no existe realmente como algo sustantivo ${ }^{35}$, y por ello, la identificación resultante es una fuente ilimitada de conflicto y sufrimiento, tanto individual como colectivo, ya que la amenaza al ego se vive como una amenaza real a la existencia de nuestro sistema vital o colectivo. El sufrimiento, muy a menudo, nace del deseo de que las cosas sean como nos gustaría que fueran, es decir, como nuestro ego desea o imagina, o del deseo de que no existan las que consideramos dañinas o desagradables. A través del ego, la experiencia consciente se vivencia como "separada», bajo la distinción de un sujeto, por un lado, y un mundo objetivado, distinto y distante, por otro, ante el que surgen las fuerzas del deseo, la aversión o la indiferencia. Este es el objeto último de la práctica de la atención plena: transcender las ilusiones de la experiencia de conciencia dual con el fin de superar el sufrimiento.

\section{Conclusiones}

A lo largo de esta exposición hemos presentado diversas líneas de investigación que hoy día se hacen eco de la cuestión suscitada por la práctica de la atención plena y el intento de explicar la experiencia resultante de la misma. El encuentro entre Oriente y Occidente significa un reto conjunto a la hora de

35 En esto coincide la tradición budista con la moderna neurociencia como puede verse en la obra de R. Llinás (2003). El cerebro y el mito del yo. Madrid: Norma Editorial, pp. 118 ss. Donde el autor explica la generación del sentido del yo desde la coherencia del sistema tálamocortical, o los experimentos sobre el cerebro escindido de Roger Sperry (Nobel 1981) y Michael Gazzaniga. 
dar respuesta a los procesos cognitivos descritos por las tradiciones meditativas con un lenguaje metafórico y con metodología práctica basada en experiencia de primera persona, lo cual, en muchos casos resulta extraño a nuestra cultura científica. El nacimiento de la metodología de entrenamiento de la atención plena, precisamente en contextos científicos (medicina, psicología, neurociencia), ha puesto de relieve el potencial de las antiguas tradiciones contemplativas y, al mismo tiempo, ha cambiado el punto de vista sobre estas prácticas y sus consecuencias a nivel cognitivo, de comprensión de la realidad, éticas, medioambientales, sociales etc.

Para la tradición, las prácticas basadas en el desarrollo de la atención plena son la respuesta a un modo diferente de vivir la experiencia, de modo que se minimice el sufrimiento inherente a la experiencia ordinaria. El reto surgido hoy día del diálogo que se ha abierto entre estos dos modelos epistemológicos es profundizar en la capacidad humana de transformar los patrones cognitivos y con ellos la propia experiencia, así como el estudio de los correlatos neuronales de este proceso de transformación. El futuro de esta investigación no se ciñe a la mera especulación sobre descripciones de fenómenos, sino yendo un paso más allá, se trata de entrar en dimensiones diferentes a nivel cognitivo y emocional de la realidad habitual en la que nos desenvolvemos con consecuencias experimentales y relacionales concretas cuyas consecuencias afectan a modos de vivir y en último término a la felicidad como experiencia de vida. Ciencia y tradiciones, caminando juntas, pueden abrir un modelo nuevo de afrontar la vida que permita aumentar la sabiduría y afrontar la vida como crecimiento.

Queda para una posterior investigación la relación entre la propia experiencia de conciencia no dual y la influencia del marco hermenéutico en la comprensión, pedagogía y educación del proceso de apertura a la experiencia.

\section{Agradecimientos}

A María Teresa Román, maestra, amiga y confidente. Compartimos inquietudes e investigaciones, y antes o después, también compartiremos destino. Mientras dure mi memoria no te olvidaré. 


\section{Bibliografía}

Austin, J. H. (2010). "La sabiduría y la comprensión desinteresadas. Un puente talámico", en AA.VV. La espiritualidad a Debate. El estudio científico de lo trascendente. Barcelona: Kairós.

Blackmore, S. (2011). El Zen y el arte de la consciencia. Barcelona: Paidós.

Barceló, T. (2008). "La filosofía de lo implícito de Eugene Gendling", en Miscelanea Comillas 66, núm. 129, pp. 413-438.

Claxon, G. (2016). Inteligencia Corporal. ¿Por qué tu mente necesita el cuerpo mucho más de lo que piensa? Barcelona: Plataforma actual.

Damasio, A. (2010). Y el cerebro creó al hombre. ¿Cómo pudo el cerebro generar emociones, sentimientos, ideas y el yo? Barcelona: Editorial Destino.

(2011). En busca de Spinoza. Neurobiología de la emoción y los sentimientos. Barcelona: Editorial Destino.

Deikmann, A. J. (2012) Experimental Meditation. http://www.deikman.com/ experimental.html

Frankl, V. (1987). El hombre doliente. Fundamentos antropológicos de la psicoterapia. Barcelona: Herder.

Gadamer, H.-G. (51993). Verdad y Método. Fundamentos de una hermenéutica filosófica. Salamanca: Sígueme.

Gurwitsch, A. (1979). El campo de la conciencia. Un análisis fenomenológico. Madrid: Alianza Editorial.

Harvey, P. (1998). El budismo. Madrid: Cambridge University Press.

Herrán, A. de la (2006). "Los Estados de Conciencia: Análisis de un Constructo Clave para un Enfoque Transpersonal de la Didáctica y la Formación del Profesorado", en Tendencias Pedagógicas 11, pp. 103-154.

JaKendorfF, R. (1998). La conciencia y la mente computacional. Madrid: Visor.

Kaвat-Zinn, J. (2016). Vivir con plenitud las crisis. Cómo utilizar la sabiduría del cuerpo $y$ de la mente para enfrentarnos al estrés, el dolor y la enfermedad. Barcelona: Kairós.

Lati Rimpoche (2001). ¿Qué es la mente? La explicación del budismo tibetano. Alicante: Dharma.

Lipton, B. (2008). Raising the Threshold of Abundance in Our Material. Spiritual and Emotional Lives. Santa Rosa, California: J. M. House, Elite Books.

(2007). Biología de las creencias. La liberación del poder de la consciencia, la materia y los milagros. Madrid: Palmyra. 
Lutz, A.; Jha, A. P.; Dunne, J. D., \& Saron, C. D. (2015). "Investigating the phenomenological matrix of mindfulness-related practices from a neurocognitive perspective", en American Psychologist 70 (7), pp. 632-658.

LLINÁs, R (2003). El cerebro y el mito del yo. Madrid: Norma Editorial.

Merleau-Ponty, M. (1994). Fenomenología de la percepción, Barcelona: Planeta Agostini.

Purves, D. (dir.). AA.VV. (2008). Neurociencia, Madrid, Bogotá, Buenos Aires, Caracas, México: Editorial Panamericana.

Ravagnan, L.M. (1965). "Concepción fenomenológica del campo de la consciencia", en Revista de Psicología 2, pp. $49-54$ (online) http://www.memoria.fahce.unlp.edu. ar/art_revistas/pr.861/pr.861.pdf

Ricoevr, P.; Changeux, J.-P. (1999). Lo que nos hace pensar. La naturaleza y la regla. Barcelona: Península.

Román López, M. T. (2017). La exploración de la consciencia en Oriente y Occidente. Barcelona: Kairós.

(2016). 'Paisajes no-duales en el pensamiento oriental", en Éndoxa, pp. 23-46.

(2009). “Un acercamiento a las grandes tradiciones de meditación”, en Cuadernos del Marqués de San Adrián: revista de humanidades 6, pp. 181-194.

Rosenzweig, M. R.; Breedlove, S. M.; Watson, N. V. (2005). Psicobiología. Una introducción a la neurociencia conductual, cognitiva y clínica. Barcelona: Ariel.

DE LA Rubia, F.J. (2009). La conexión divina. La experiencia mistica y la neurobiología. Barcelona: Ed. Crítica.

Russel, B. (2005). Historia de la Filosofia. Barcelona: RBA.

Siegel, D. J. (2011). Mindsight. La nueva ciencia de la transformación personal. Barcelona: Paidós.

(2012). Mindfulness y psicoterapia. Técnicas prácticas de atención plena para psicoterapeutas. Barcelona: Paidós.

Siegel, R. (2011). La solución Mindfulness. Prácticas cotidianas para problemas cotidianos, Bilbao: Desclée Brower.

Simón, V. (2006). "Mindfulness y Neurobiología", en Revista de Psicoterapia XVII, núm. 66/67, pp. 5-30.

Thich Nhat Hanh (1978). Claves del Zen. Salamanca: Sígueme.

Tola, F; Dragonetti, C. (1980). El Budismo Mahayana. Buenos Aires: Kier.

Varela, F.; Tomson, E.; Rosh, E. (1997). De cuerpo presente. Las ciencias cognitivas y la experiencia humana. Barcelona: Gedisa editorial. 
(1999). "Four batons for the future of cognitive science", en Envissioning Knowledge, B. Wiens (ed.), Dumont: Cologne.

Wallace, B.A. (2009). La ciencia de la mente. Cuando la ciencia y la espiritualidad se encuentran. Barcelona: Kairós.

Zubiri, X. (2004). Inteligencia Sentiente. Madrid: Tecnos.

Recibido: 8/01/2018

Aceptado: 1/06/2018

Este trabajo se encuentra bajo una licencia de Creative Commons ReconocimientoNoComercial-SinObraDerivada 4.0

\section{(C)

